\title{
Compatibility and Morphology in Polyurethane and Polystyrene Ionomeric Interpenetrating Polymer Networks
}

\author{
K. H. Hsieh, L. M. ChOU, and Y. C. ChIANG \\ Department of Chemical Engineering, National Taiwan University, \\ Taipei, Taiwan 10764, R.O.C.
}

(Received April 4, 1988)

\begin{abstract}
Interpenetrating Polymer Networks (IPNs), composed of polyurethane (PU) and poly(styrene-acrylic acid) (PSAA), with containing mutual opposite charge groups, i.e., tertiary amine group in PU and carboxyl groups in PSAA, were prepared in PU/PSAA ratio of 75/25 (PUdominated), and 25/75 (PSAA-dominated). The compatibility and morphology of these IPNs were investigated through dynamic mechanical analysis and scanning electronic microscopy studies. Compatibility of IPNs was greatly enhanced through the introduction of charge groups into the system. There are different morphology and dynamic mechanical behaviours for PU/PSAA alloys between PU-dominated and PSAA-dominated a!loys. PSAA in the PU-dominated alloys was found to aggregate to the hard segment of the PU matrix, resulting in heterogeneous distribution of hard/soft segments in morphology and having little effect on the shift of the temperature transition while PU in PSAA-dominated alloys was found to be distributed homogeneously in the PSAA matrix.
\end{abstract}

KEY WORDS Interpenetrating Polymer Network (IPN) / Morphology / Dynamic Mechanical Analysis / Polyurethane and Polystyrene Ionomer / Compatibility /

Interpenetrating Polymer Networks (IPNs) evolves permanent entanglements between polymers by virtue of interpenetrating effects rather than by covalent chemical bonds. Such entanglements will enhance the crosslinking density of the resultant IPNs. The IPNs will create characteristic properties suitable for special applications. The free volume of IPNs reduces as the interpenetrating networks increase and, as a result, the mechanical strength increases and exceeds that of the constituents.

IPNs from rubbery polyurethane (PU) and rigid polystyrene (PS) at different composition may promote compatibility between PSreinforced PU or PU-toughened PS, since compatibility between PU and PS is poor due to the significant discrepancy in the solubility parameters between them.

From the viewpoint of thermodynamics, phase separation can be produced during po- lymerization resulting from insignificant penetrating effects due to a positive value of the free energy of mixing. ${ }^{1,2)}$ By increasing intermolecular attractions through the introduction of opposite charge groups into the polymer components to improve compatibility, proposals ${ }^{3-10}$ have been proved successful.

In this paper, $\mathrm{N}$-methyl diethanolamine (MDEA) was introduced into PU and AA to PSAA to impart attractions from tertiary amines and carboxyl groups in the polymer alloys. Through dynamic mechanical analysis and morphology studies, discussions have been given on the compatibilities of the polymer alloys containing opposite charge groups.

\section{EXPERIMENTAL}

Table I shows the materials with the designations used for the research. Polyol (PTMO 
1000) was degassed at $70^{\circ} \mathrm{C}$ under vacuum overnight before being applied. Sytrene monomer (S) was distilled under vacuum to remove the inhibitor. Other agents involved in Table I were used as received.

\section{Preparation of Full-IPNs, Semi-IPNs and \\ Linear Blends}

PU prepolymers at $5.6 \% \mathrm{NCO}$ determined by di- $n$-butylamine titration method, ${ }^{11}$ were prepared by reacting 2 equivalent $4,4^{\prime}$-methylene bis(phenyl isocyanate) (MDI) with one equivalent poly(tetramethylene oxide) glycol (PTMO). PU prepolymer was mixed with a mixture of one equivalent MDEA or triethanolamine (TEA) with suitable composition of sytrene monomer (S), acrylic acid (AA), divinyl benzene (DVB), and benzoyl peroxide (BPO). The mixture was agitated vigorously for three minutes at $80^{\circ} \mathrm{C}$, and then degassed for 30 seconds. Afterwards, it was cast in an aluminum mold for reaction at $80^{\circ} \mathrm{C}$ for 24 hours, and postcured at $100^{\circ} \mathrm{C}$ for another $24 \mathrm{~h}$. As for the preparation of the linear blends, the crosslinking agent, DVB, for
PSAA has to be removed and MDEA takes the place of TEA in the mixture. For SemiIPNs preparation, either crosslinking agent has to be replaced by difunctional reactants. For this study, PU/PSAA alloys at ratios of $75 / 25$ and $25 / 75$ were prepared. Samples were kept in a disccator at $50 \%$ R.H. for at least three days before being tested for physical and mechanical properties.

\section{Testing Methods}

Rheovibron Model DDV-IIC in the temperature range of $-80^{\circ} \mathrm{C}$ to $160^{\circ} \mathrm{C}$ was used to determine the dynamic mechanical properties. Frequency was set at $110 \mathrm{~Hz}$, heating rate kept at $1-2^{\circ} \mathrm{C} \mathrm{min}^{-1}$ in the transition regions, and $3-5^{\circ} \mathrm{C} \mathrm{min}^{-1}$ in the non-transition regions.

A morphological study was performed with the aid of a scanning electronic microscope (SEM). Microphotographs were taken of the surface of the samples, which were fractured in liquid nitrogen and coated with gold powder.

Table I. Materials

\begin{tabular}{lll}
\multicolumn{1}{c}{ Designation } & \multicolumn{1}{c}{ Composition } & \multicolumn{1}{c}{ Supplier } \\
\hline MDI & $\begin{array}{l}\text { 4-4'methylene bis(phenyl isocyanate) } \\
\text { Poly(tetramethylene oxide) } \\
\text { glycol M.W. }=1002\end{array}$ & $\begin{array}{l}\text { Bayer Chemical Co. } \\
\text { Union Carbide Chemical Co. }\end{array}$ \\
MDEA 1000 & Methyl diethanol amine & Merck Chemical Co. \\
TEA & Triethanolamine & Wako Pure Chemical Co. \\
S & Styrene & Hayashi Pure Chemical Co. \\
AA & Acrylic acid & Merck Chemical Co. \\
DVB & Divinyl benzene & Merck Chemical Co. \\
BPO & Benzoyl peroxide & Merck Chemical Co. \\
DBA & Di- $n$-butylamine & Hayashi Pure Chemical Co. \\
PU & PTMO $1000 /$ MDI/MDEA (or TEA) & \\
PS (or PSAA) & $=1 / 2 / 1$ (equivalence) & \\
LPU/LPSAA15 & S (or S/AA)/DVB/BPO & \\
CPU/CPSAA15 & $=28.5 / 1.5 / 0.6($ weight fraction) & \\
LPU/CPSAA15 & Linear blend of PU and PSAA & \\
& with 15 mol $\%$ AA & \\
\hline
\end{tabular}




\section{RESULTS AND DISCUSSION}

\section{Dynamic Mechanical Analysis}

From Figures 1 and 2, we observed that the $E^{\prime}$ curves have two declining stages for either Full-IPNs (Figure 1) or linear blends (Figure 2 ) in the absence of AA in PSAA at PU/PSAA ratio of $25 / 75$. One declining stage which emerged as 15 or $30 \mathrm{~mol}^{\%} \mathrm{AA}$ was introduced into PSAA, meaning that the introduction of AA serves to impart a homogeneous property of the resultant alloys.

From the $E^{\prime \prime}$ curves in Figures 1 and 2, two separating transition peaks in the absence of AA in PSAA were observed with one at low temperature representing the transition of the PU phase, and the other at high temperature indicating the PSAA phase. These separating transitions resulting from the poor compatibility between both components were caused by the rather significant difference in the solubility parameter falling between them. ${ }^{12-14}$

Introduction of $15 \mathrm{~mol} \%$ AA into PSAA increased its compatibility through intermolecular attractions by the tertiary amine and

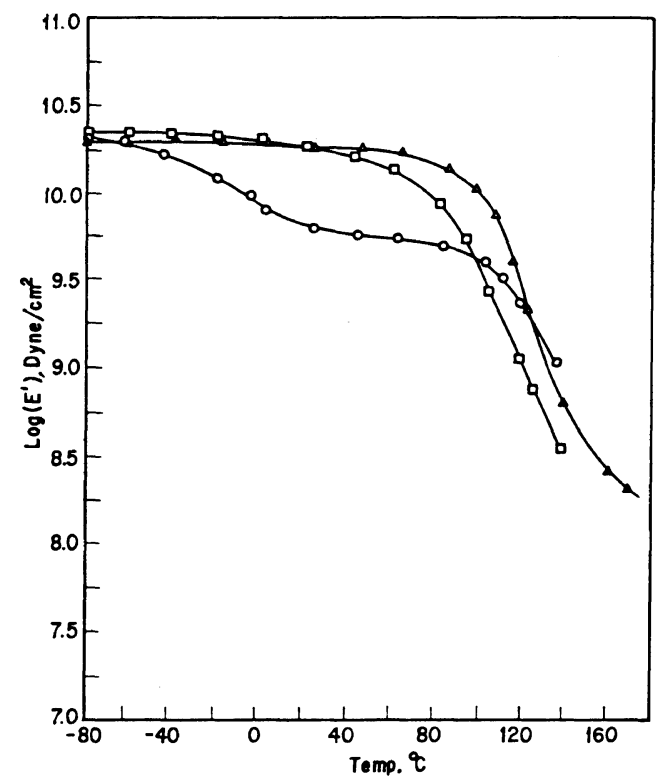

carboxyl group in the system, thus forming a combined broad transition peak between two transition peaks of the polymer components. As the AA content was increased up to $30 \mathrm{~mol} \%$, the transition peak turned narrower in peak shape. This indicates that the compatibility can be further improved with continual increase of AA content. The transition peak for the presence of AA in the linear blend system is even broader than that in the case of Full-IPN system. This shows that compatibility has been improved in linear blends, though not so satisfactorily as that in the FullIPNs, since Full-IPNs possess permanent entanglements which force polymer chains to hold together during polymerization and thus increase its compatibility. ${ }^{15}$

Figure 3 shows the temperature dependence of $E^{\prime}$ and $E^{\prime \prime}$ for polymer alloys at PU/PSAA at $25 / 75$ and with $15 \mathrm{~mol} \%$ AA in PSAA. $E^{\prime \prime}$ curves have broad transitions at high temperatures near that of the crosslinked PSAA. Transition peaks emerged at different temperatures with different heights indicate the various degrees of compatibility as follows:

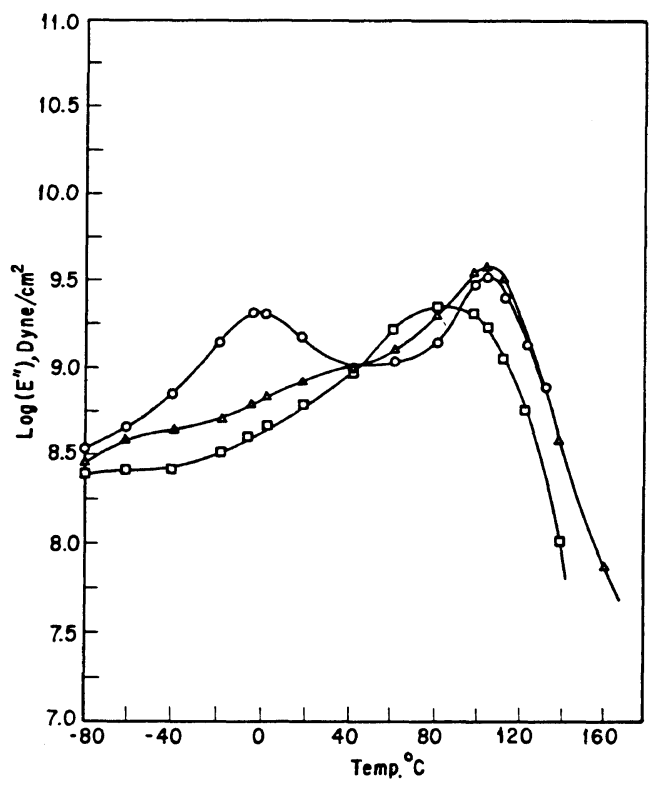

Figure 1. Temperature dependence of $E^{\prime}, E^{\prime \prime}$ of CPU/CPSAA Full-IPNs at a ratio of 25/75 with CPSAA containing various AA content $\left(\mathrm{mol}^{\%}\right)$ : $-\mathrm{O}-, 0 ;-\square-, 15 ;-\triangle-, 30$. 

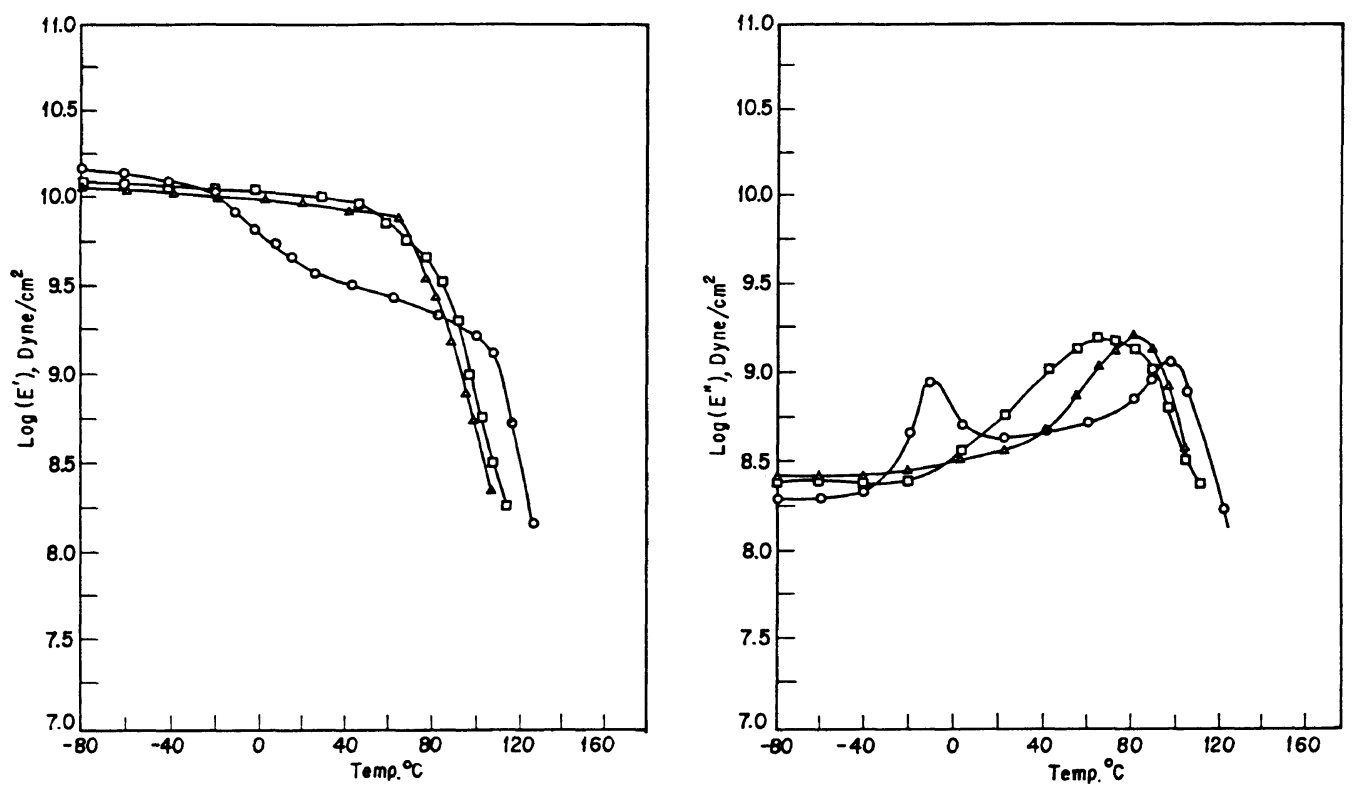

Figure 2. Temperature dependence of $E^{\prime}, E^{\prime \prime}$ of LPU/LPSAA linear blends at a ratio of 25/75 with LPSAA containing various AA content $\left(\mathrm{mol}^{\%}\right)$ : $-\mathrm{O}-, 0 ;-\square-, 15 ;-\triangle-, 30$.
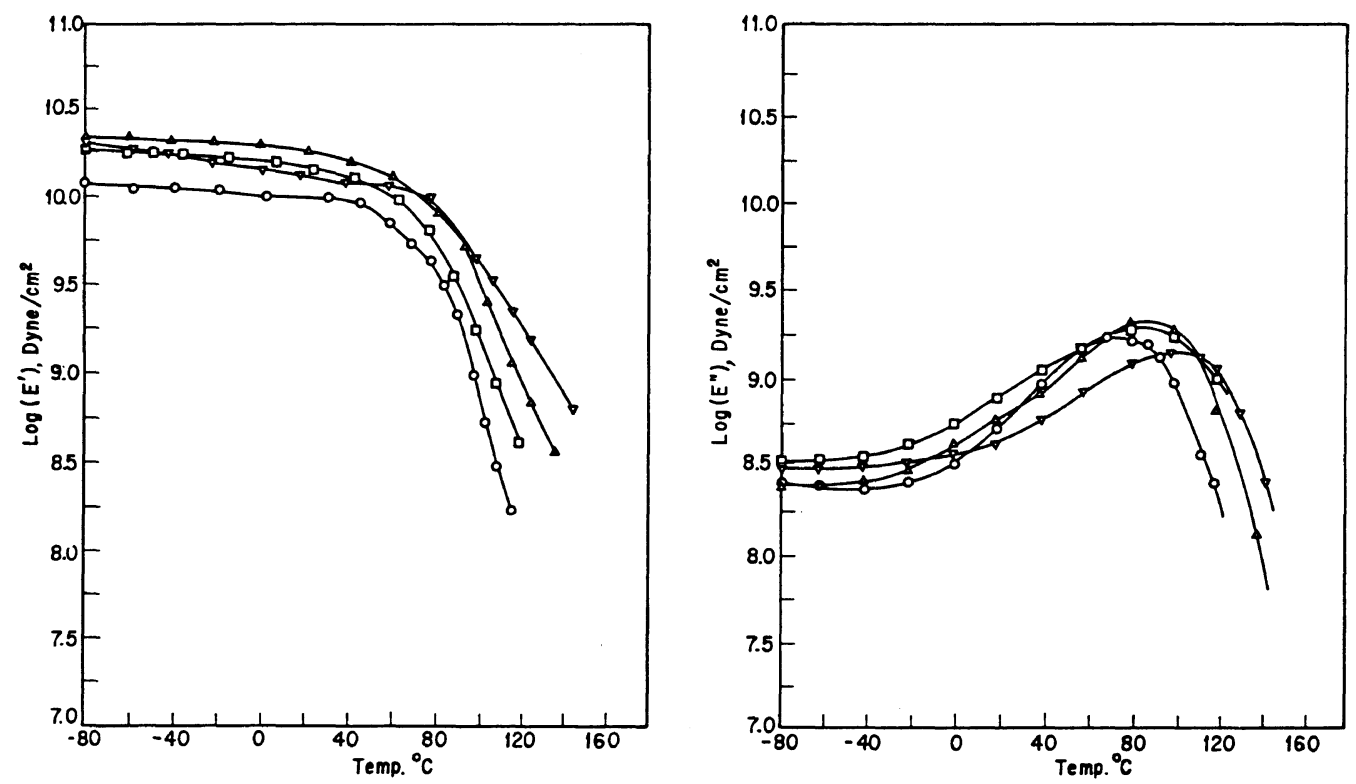

Figure 3. Temperature dependence of $E^{\prime}, E^{\prime \prime}$ of PU/PSAA alloys at a ratio of $25 / 75$ with $15 \mathrm{~mol} \% \mathrm{AA}$ in PSAA: - $\triangle$, CPU/CPSAA $15 ;-\square-$, CPU/LPSAA $15 ;-\nabla-$, LPU/CPSAA $15 ;-0-$, LPU/ LPSAA 15.

Full-IPN $>$ PSAA-crosslinked Semi-IPN $>$ PU-crosslinked Semi-IPN $>$ Linear blend. The reasons why the degree of compatility of
PSAA-crosslinked polymer alloys is higher than that in the case of PU-crosslinked alloys can be explained by the molecular chain dif- 
fusion theory. ${ }^{16.17}$ In early stage of polymerization, the viscosity of PU prepolymer is so high that both the linear and crosslinking PU reactions failed to change drastically in the viscosity and diffusion speed of PU chains during the polymerization. However, the viscosity of S-AA in crosslinking reactions increases faster than in linear reactions. As a result, PSAA in crosslinking reaction was not given sufficient time to diffuse because of higher viscosity building up, making PSAAcrosslinking alloys allow more interpenetrating structures than PU-crosslinking systems, leading to better compatibility.

Similar phenomena as mentioned above were observed for alloys at PU/PSAA at 75/25 as shown in Figures 4 to 6 . Two transition peaks for polymer alloys without AA in the system converged to one transition peak as the AA was incorporated, and the shift of $E^{\prime \prime}$ transition peak to a higher temperature increased with increasing AA content but was not so significant as that of PU/PSAA alloys at $25 / 75$ ratio. This is attributed to the transition peak of PU-dominated alloys showing mainly

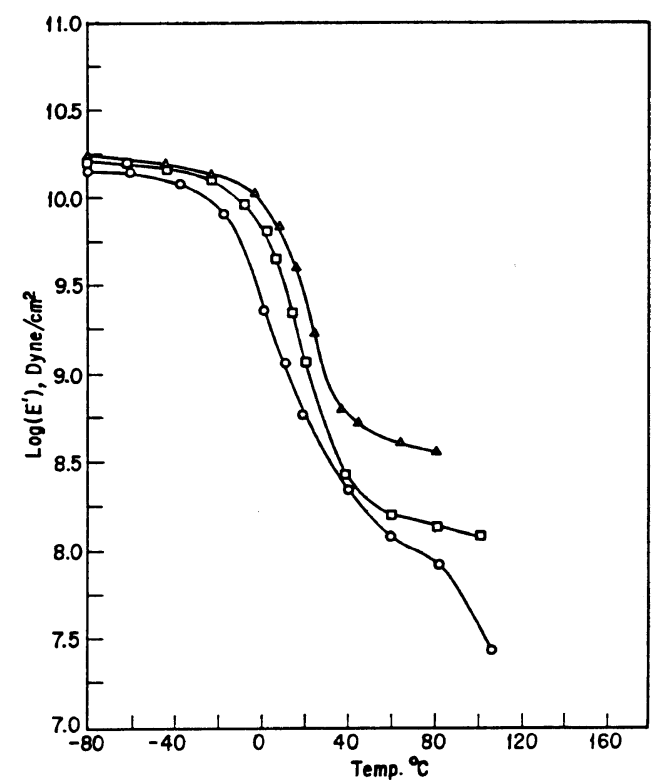

the transition of the soft segment of PU rather than that of the hard one. While PSAA was incorporated in the system, it was attracted by the tertiary amine group in the hard segment of PU and therefore PSAA agglomerated in PU hard segment, instead of in PU soft segment. This results in less effect on the shift of transition peaks of PU-dominated alloys.

\section{Scanning Electron Microscopy}

Microphotographs taken of PU/PSAA polymer alloys are shown in Figures 7 and 8, and we can see that the polymer alloys without AA in the system are dispersed phases scattered in the matrix in the form of round particles, (Figures 7(a), 7(c) and Figures 8(a), 8(c)).

Looking at the average diameter of the particles and their occupied area fractions listed in Table II, once the introduction of AA into PSAA is made, particle disappears. It becomes clear that the phase separation diminishes as AA is introduced. From Table II, the particle in Full-IPNs is invariable larger than that in the linear blends. This is probably due to the lesser degree of compatibility as a result

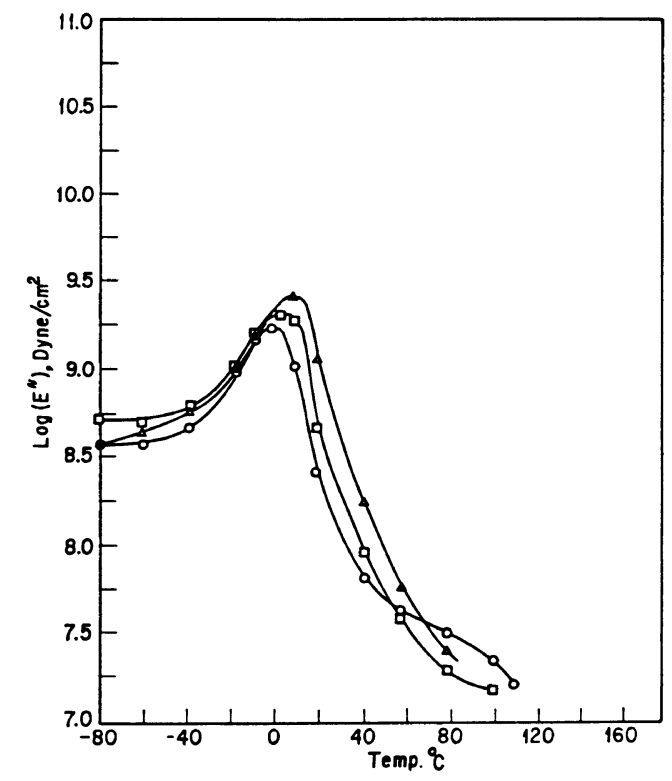

Figure 4. Temperature dependence of $E^{\prime}, E^{\prime \prime}$ of CPU/CPSAA Full-IPN at a ratio of 75/25 with CPSAA containing various AA content $\left(\mathrm{mol}_{\%} \%\right)$ : - $\mathrm{O}-, 0 ;-\square-, 15 ;-\triangle-, 30$. 

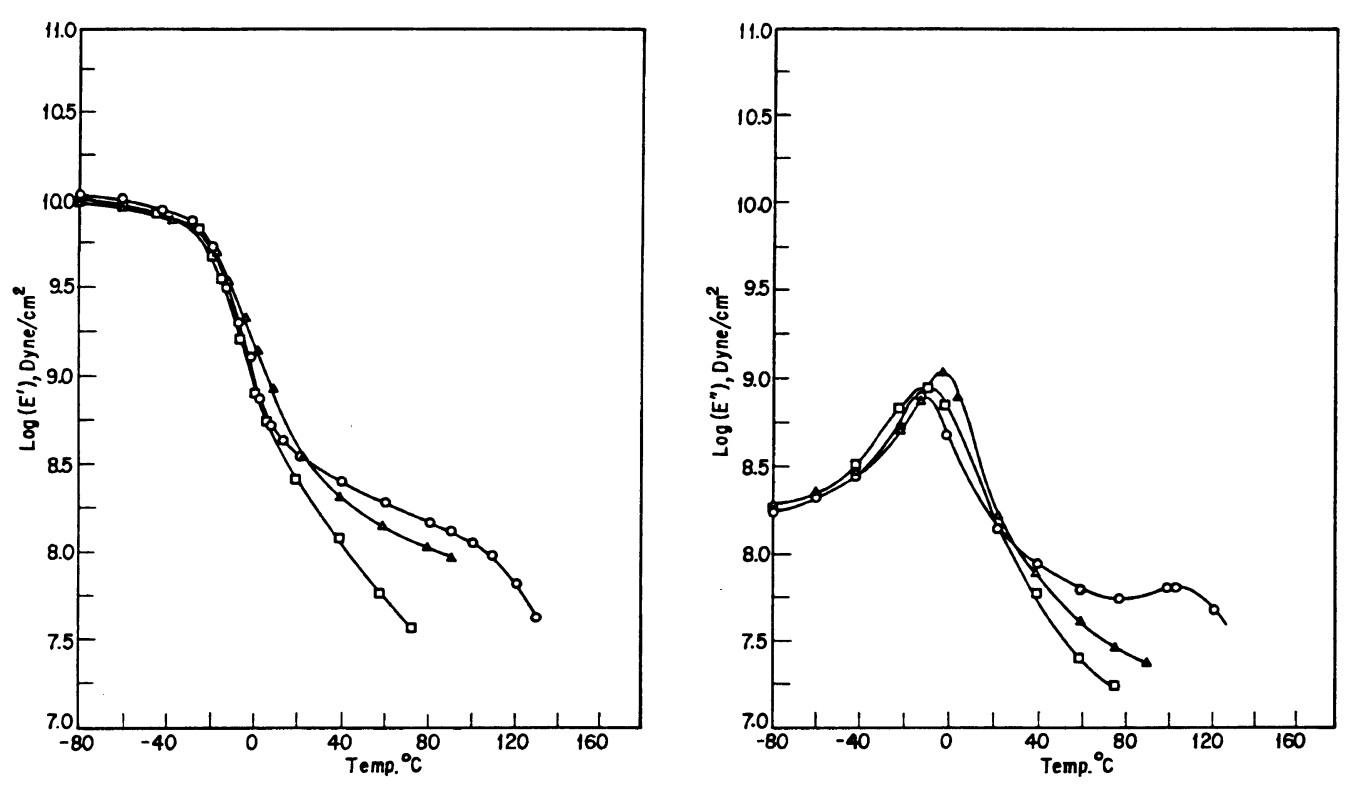

Figure 5. Temperature dependence of $E^{\prime}, E^{\prime \prime}$ of LPU/LPSAA linear blends at a ratio of 75/25 with LPSAA containing various AA content $\left(\mathrm{mol}^{\%}\right)$ : $-\mathrm{O}-, 0 ;-\square-, 15 ;-\triangle-, 30$.
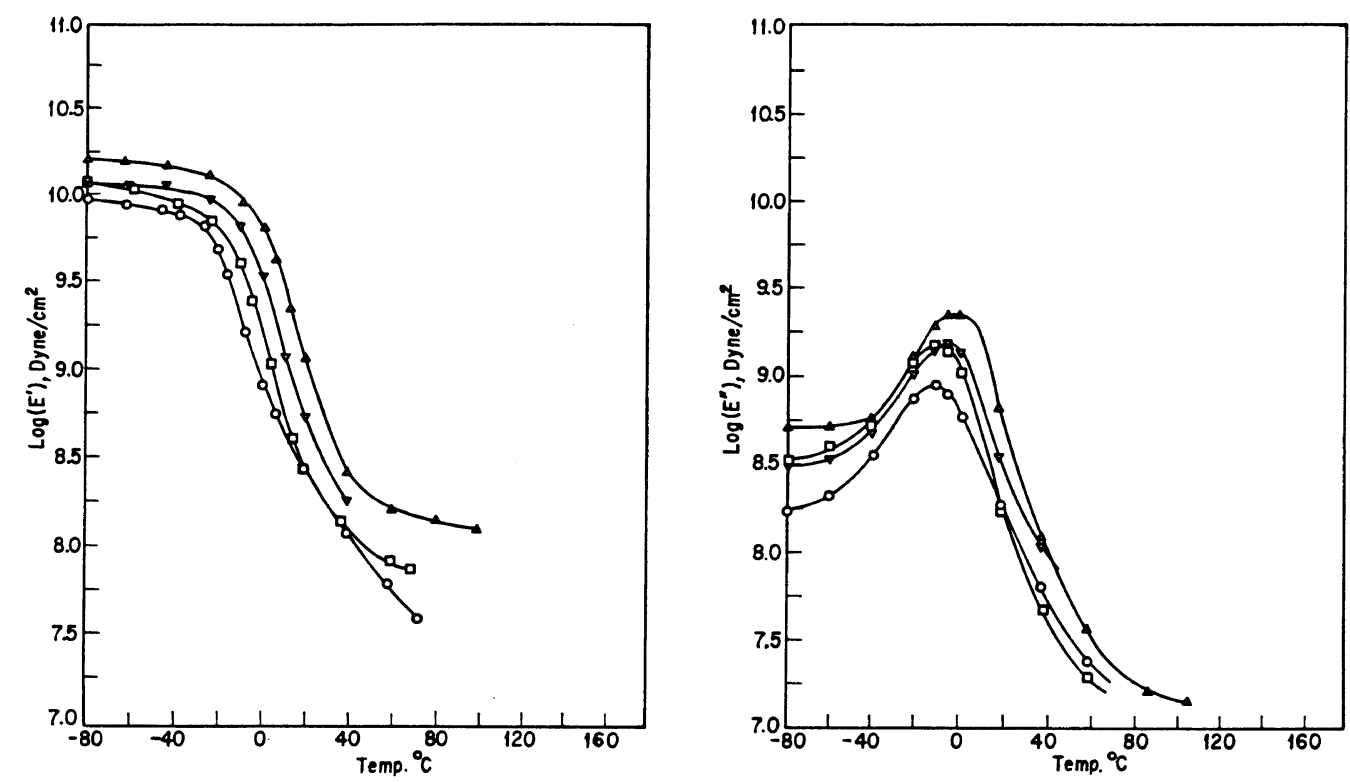

Figure 6. Temperature dependence of $E^{\prime}, E^{\prime \prime}$ of PU/PSAA alloys at a ratio of $75 / 25$ with $15 \mathrm{~mol} \%$ AA in PSAA: $-\triangle-$, CPU/CPSAA $15 ;-\square-$, CPU/LPSAA $15 ;-\nabla-$, LPU/CPSAA $15 ;-O-$, LPU/ LPSAA 15.

of the crosslinking effect.

Furthermore, the dispersed particles in PUdominated alloys is larger than that in PS- dominated alloys. We also see $57.2 \%$ for the CPU/CPS alloyws at 25/75 in Table II showing the occupied area fraction of the dispersed 


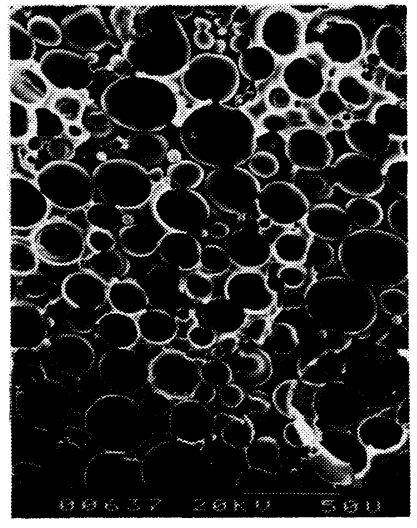

(a)

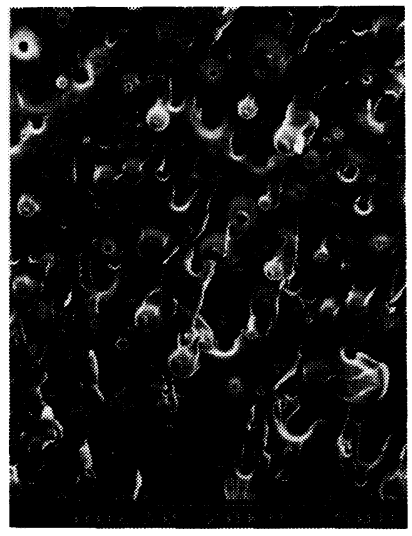

(c)

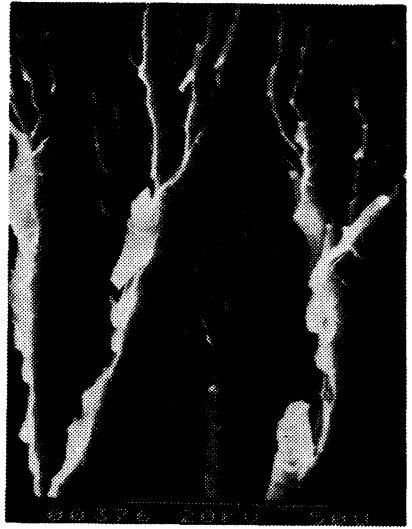

(b)

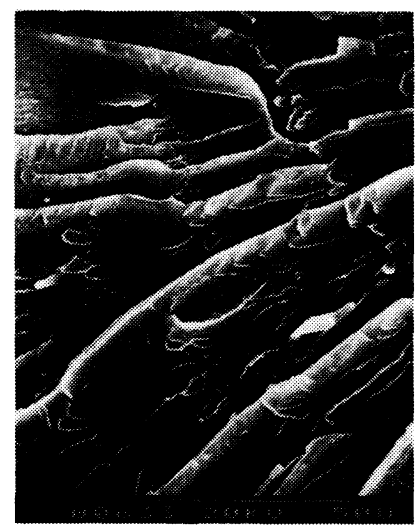

(d)

Figure 7. Microphotographs of SEM for PU/PSAA=25/75 polymer alloys: (a) CPU/CPS; (b) CPU/ CPSAA15; (c) LPU/LPS; (d) LPU/LPSAA15.

Table II. The average particle size and occupied area of dispersed phase of PU/PSAA Full-IPNs and linear blends in the martix

\begin{tabular}{cccc}
\hline Sample & $\begin{array}{c}\text { PU/PSAA } \\
\text { weight } \\
\text { ratio }\end{array}$ & $\begin{array}{c}\text { Average } \\
\text { particle } \\
\text { size } / \mu \mathrm{m}\end{array}$ & $\begin{array}{c}\text { Particle } \\
\text { occupied area/ } \\
\text { unit area/\% }\end{array}$ \\
\hline CPU/CPS & $75 / 25$ & 71.9 & 25.5 \\
LPU/LPS & $75 / 25$ & 10.7 & 7.8 \\
CPU/CPS & $25 / 75$ & 17.2 & 57.2 \\
LPU/LPS & $25 / 75$ & 4.4 & 15.3 \\
\hline
\end{tabular}

particles. Assuming the cross-sectional area of the dispersed phase is proportional to its volume, ${ }^{18}$ it becomes obvious that the dispersed particles are composed of PU and PSAA altogether.

The microphotographs of SEM of CPU/ CPS and LPU/LPS ratios of 75/25 in Figures $8(\mathrm{a})$ and $8(\mathrm{c})$ indicate clearly that there is stress rupture on the dispersed particles. This indicates that the PS would be the dispersed phase in the PU matrix. This was not noted for the CPU/CPS and LPU/LPS ratios of 25/75 in Figures 7(a) and 7(c) respectively, and PU thus appears to be the dispersed phase in the PS continuous phase. Tiny grains which exist in Figure 7(a) seen in white color and different from PU particles, may be particles of PS. 


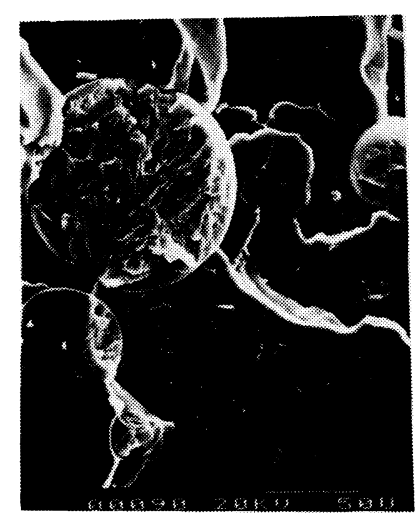

(a)

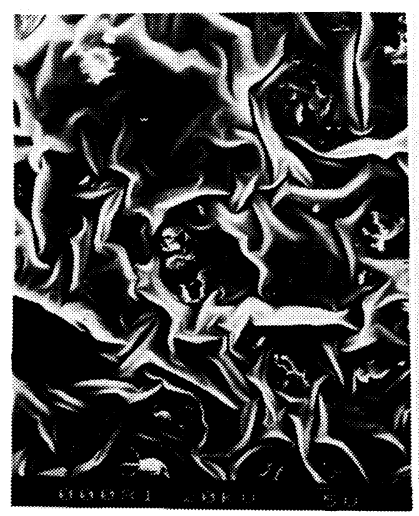

(c)

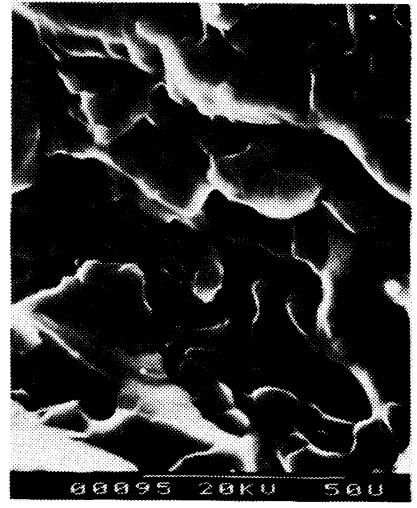

(b)

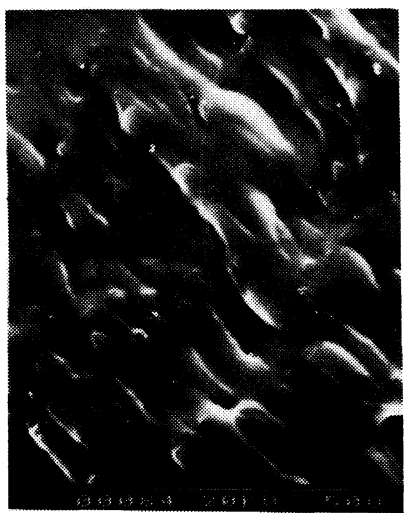

(d)

Figure 8. Microphotographs of SEM for PU/PSAA $=75 / 25$ polymer alloys: (a) CPU/CPS; (b) CPU/CPSAA15; (c) LPU/LPS; (d) LPU/LPSAA15.

\section{Glass Transition Temperature}

The transition temperatures of PU/PSAA alloys in Full-IPNs, Semi-IPNs and Linear blends are listed in Table III. Two transition temperatures can be observed in Full-IPNs and Linear blends without the presence of a charge group in the system. However, one transition temperature is observed for the alloys containing a charge group. This single transition temperature $\left(T_{\mathrm{g}}\right)$ will rise with increase of AA content in the system.

In regard to differences between the observed $T_{\mathrm{g}} \mathrm{s}$ and those calculated, we found that the difference $\left(\Delta T_{\mathrm{g}}\right)$ at PU/PSAA ratio of $25 / 75$ is much samller than that at $75 / 25$. This indicates that the transition peak at low temperature $\left(T_{\mathrm{g} 1}\right)$ is in fact the transition temperature of the PU soft segment. PSAA introduced is concentrated on the tertiary amine group in the hard segment of PU as mentioned before, and thus the non-uniform fractured surface can be observed from the SEM micrographs as shown in Figures 8(b) and 8(d) with PU/PSAA alloys at $75 / 25$.

In other words, $T_{\mathrm{g} 1}$ is not appreciably affected by the introduction of PSAA into PUdominated alloys. Therefore, the calculated value of $T_{\mathrm{g}}$ under such a condition differs noticeably from the value determined by dynamic mechanical analysis. 
Polyurethane and Polystyrene Ionomeric IPN

Table III. Glass transition temperatures of PU/PSAA Full-IPNs, Semi-IPNs, and linear blends

\begin{tabular}{|c|c|c|c|c|c|}
\hline Sample & $\begin{array}{c}\text { PU/PSAA } \\
\text { weight ratio }\end{array}$ & $\begin{array}{c}T_{\mathrm{g} 1} / \mathrm{K} \\
\text { (from } E^{\prime \prime} \text { ) }\end{array}$ & $\begin{array}{c}T_{\mathrm{g} 2} / \mathrm{K} \\
\text { (from } E^{\prime \prime} \text { ) }\end{array}$ & $T_{\mathrm{gcal}}^{*} / \mathrm{K}$ & $\begin{aligned} & \Delta T_{\mathrm{g}} / \mathrm{K} \\
= & T_{\mathrm{gcal}}-T_{\mathrm{g}}\end{aligned}$ \\
\hline CPS & $0 / 100$ & - & 383 & - & - \\
\hline CPSAA 15 & $0 / 100$ & 一 & 407 & - & - \\
\hline CPSAA 30 & $0 / 100$ & - & 423 & - & - \\
\hline LPS & $0 / 100$ & - & 375 & - & - \\
\hline LPSAA 15 & $0 / 100$ & - & 393 & - & - \\
\hline LPSAA 30 & $0 / 100$ & - & 413 & - & - \\
\hline CPU & $100 / 0$ & 270 & - & - & - \\
\hline LPU & $100 / 0$ & 261 & - & - & - \\
\hline CPU/CPS & $75 / 25$ & 273 & 355 & - & - \\
\hline CPU/CPSAA 15 & $75 / 25$ & 271 & - & 304 & 33 \\
\hline CPU/CPSAA30 & $75 / 25$ & 284 & - & 308 & 24 \\
\hline CPU/LPSAA15 & $75 / 25$ & 258 & - & 300.75 & 43 \\
\hline LPU/CPSAA15 & $75 / 25$ & 265 & - & 297.5 & 32 \\
\hline LPU/LPSAA15 & $75 / 25$ & 262 & - & 294 & 32 \\
\hline LPU/LPSAA30 & $75 / 25$ & 280 & - & 299 & 19 \\
\hline CPU/CPS & $25 / 75$ & 272 & 376 & - & - \\
\hline CPU/CPSAA 15 & $25 / 75$ & - & 365 & 372.75 & 8 \\
\hline CPU/CPSAA30 & $25 / 75$ & - & 378 & 384.75 & 7 \\
\hline CPU/LPSAA15 & $25 / 75$ & - & 351 & 362.25 & 11 \\
\hline LPU/CPSAA15 & $25 / 75$ & - & 376 & 370.5 & -6 \\
\hline LPU/LPSAA15 & $25 / 75$ & - & 349 & 360 & 11 \\
\hline LPU/LPSAA 30 & $25 / 75$ & - & 355 & 375 & 20 \\
\hline LPU/LPS & $25 / 75$ & 262 & 377 & - & - \\
\hline LPUS/LPS & $75 / 25$ & 262 & 377 & - & - \\
\hline
\end{tabular}

* $T_{\mathrm{gcal}}=W_{\mathrm{PU}} T_{\mathrm{g} \mathrm{PU}}+W_{\mathrm{PSAA}} T_{\mathrm{gPSAA}}$ where $T_{\mathrm{gPU}}, T_{\mathrm{gPSAA}}$, and $W_{\mathrm{PU}}, W_{\mathrm{PSAA}}$ are glass transition temperatures and weight fractions of PU and PSAA, respectively.

\section{CONCLUSIONS}

Owing to the ionic interaction between the tertiary amine in PU and the carboxyl group in PSAA, the introduction of AA into the system increases the compatibility for the IPNs composed of PU and PSAA.

SEM micrographs indicated the introduction of AA into PSAA to eliminate the dispersed phase in the alloys resulting in homogeneous morphology.

The dynamic mechanical analysis of such alloys in the presence of AA in PSAA shows a single transition peak consistent with SEM observation.

Acknowledgement. Support of the National Science Council, Taipei, Taiwan, R.O.C. through Grant No. NSC-75-0405-E002-03 is greatly appreciated.

\section{REFERENCES}

1. D. S. Lee and S. C. Kim, Macromolecules, 17, 2193 (1984).

2. V. Hueck, D. A. Thomas, and L. H. Sperling, Macromolecules, 5, 340 (1972).

3. A. Eisenberg, P. Smith, and Z. L. Zhou, Polym. Eng. Sci., 22, 1117 (1982).

4. M. Rutkowska and A. Eisenberg, J. Appl. Polym. Sci., 29, 755 (1984).

5. H. X. Xiao, K. C. Frisch, and H. L. Frisch, J. Polym. Sci., Polym. Chem. Ed., 22, 1035 (1984).

6. E. F. Cassidy, H. X. Xiao, K. C. Frisch, and H. L. Frisch, J. Polym. Sci., Polym. Chem. Ed., 22, 2667 (1984).

7. D. Klempner, K. C. Frisch, H. X. Xiao, and H. L. Frisch, Polym. Eng. Sci., 25, 488 (1985).

8. K. C. Frisch, D. Klempner, H. X. Xiao, E. Cassidy, and H. L. Frisch, Polym. Eng. Sci., 25, 758 (1985).

9. K. H. Hsieh and B. J. Wong, J. Chin. IChE, 19, 17 (1988). 
10. K. H. Hsieh and M. L. Wu, J. Chin. IChE, 19, 67 (1988).

11. C. Hepburn, Ed., "Polyurethane Elastomer," Applied Science Publishers, 1982, p 280.

12. K. C. Frisch, D. Klempner, S. Migdal, and H. L. Frisch, J. Appl. Polym. Sci., 12, 885 (1974).

13. S. C. Kim, D. Klempner, and K. C. Frisch, J. Appl. Polym. Sci., 21, 1289 (1977).

14. K. C. Frisch, D. Klempner, T. Antczak, and H. L.
Frisch, J. Appl. Polym. Sci., 18, 683 (1974).

15. S. C. Kim, D. Klempner, K. C. Frisch, W. Radigan, and H. L. Frisch, Macromolecules, 9, 258 (1976).

16. K. C. Frisch, D. Klempner, and H. L. Frisch, Polym. Eng. Sci., 22, 1143 (1982).

17. T. J. Hsu and L. J. Lee, Polym. Composite, 25, 951 (1985).

18. R. T. DeHoff and F. N. Rhines, Ed., "Quantitative Microscopy," McGraw Hill, New York, 1968. 